\title{
An Analysis of Synergy Degree of Primary-Tertiary Industry System in Dujiangyan City
}

\author{
Qizhi Yang \\ School of Tourism, Sichuan Agricultural University, Chengdu 611830, China \\ Tel: 86-28-8711-5330 \\ Fuhui Yan \& Feng Ye \\ School of Economics and Management, Sichuan Agricultural University, Chengdu 611830, China \\ E-mail: yefengjust106@126.com
}

Received: May 12, 2011 Accepted: May 30, 2011 doi:10.5539/ijbm.v6n8p291

\begin{abstract}
According to the characteristics of complex system and the synergetic theories, authors establish the order parameters for the primary industry system and the tertiary industry system, using order parameters describing the order degree of industry system, constituting the model assessing the synergy degree of the primary-tertiary complex industry system, analyzing the impact factor of system synergetic development, and studying the synergy degree of primary-tertiary industry system in Dujiangyan City. Studies show that: there is a positive synergy degree in the primary-tertiary industry system in Dujiangyan City, but the synergy degree is low. No efficient synergetic relationship exists between the two industry systems. By means of adjusting the employment structure, focusing on the development of special industries of agriculture, and developing the tertiary industry, especially the tourism industry as the leading industry, we can improve the synergy degree of primary-tertiary industry system.
\end{abstract}

Keywords: Dujiangyan, Primary-tertiary industry system, Degree of order, Synergy degree

\section{Introduction}

Dujiangyan City has the proper industry structure, which is in line with the laws and requirements of evolvement and development of international industry structure. According to the resource endowment of Dujiangyan City, the tourism industry has been always the leading industry of the city. And some special industries of agriculture have a good advantage of traditional planting and better mass basis. Compared to the tourism and the agriculture, the industry does not possess prominent competitive advantages. It mainly develops the resource-saving and environment-friendly industry. The primary industry and the tertiary industry have clear focuses. In the year 2009, the three industries have realized the added value 1.59 billion Yuan, 3.96 billion Yuan, and 6.14 billion Yuan respectively. The proportion of the primary industry, the secondary industry, and the tertiary industry is 13.6:33.9:52.5. And their contribution ratios to the city's economic growth are respectively 3.2\%, 40.6\%, and $56.2 \%$. However, from the perspective of real industry, the tertiary industry, in which the tourism is the leading industry, has a dominance position. Statistic data show that the tourism industry and related service industry consume an employment of 150,000 people, almost accounting for the half of the whole employment. Besides, Dujiangyan City supports the tourism as the leading industry of city economy. In the year 2009, the tourism industry realized the comprehensive revenue of 4.208 billion Yuan, increasing 26\% over 2007. The agriculture, as the basic industry of county tourism, is very important in Dujiangyan City. The Dujiangyan City aims at developing modern ecological agriculture, and focusing on special agricultural industry. Based on the construction of special agricultural products, it forms five special industries with local advantages: kiwi fruit, tea, cold water fish, pigs, vegetables, and edible fungi. And the five industries serve as the industrial support for the county tourism industry in Dujiangyan City, playing an important role. From this point of view, whether agriculture is in synergy with the tertiary industry, represented by tourism, is critical to the positive development of tertiary industry in Dujiangyan City. Meanwhile, the net income of farmers in Dujiangyan City is only 6000 Yuan plus in the year 2009. Although the number seems not so small, it is still relatively lower, compared to the income of citizens. There is a big gap between city and county. Schultz, a famous economist, has said: problems of agriculture have to be solved outside. To achieve a fast increase of farmers' income, we must find solution out of the agriculture. In Dujiangyan City, to develop the agriculture-supported county tourism is a practical way increasing farmers' income. Whether the tertiary industry, represented by tourism, is in synergy with the agriculture, has irreplaceable significance for increasing farmers' income and solving the "agriculture, rural areas, 
and farmers" problem. Therefore, based on theories of synergetics in this paper authors establish the order parameters of the primary industry and the tertiary industry to describe the degree of order of the industry system, constitute a model assessing the synergy degree of the primary-tertiary industry complex system, and analyze the impact factors affecting the synergy of system, hoping to make up reasonable industrial policies for Dujiangyan City, and driving the synergetic development of the three industries.

\section{Connotations of the synergetic development of the primary-tertiary industry system and theoretical basis}

\subsection{Basic connotations of the synergetic development of the primary-tertiary industry system}

The synergetic development of the primary-tertiary industry discussed in this paper means the synergy and coexistence of all sub-industries and industrial components in the industry system. By means of mutual effects, they can form an effective and highly-ordered integration, driving the coordinative development of industries during the self-organizing process, and promoting the rationality of industrial structure.

\subsection{Theoretical basis: theories of synergetics}

Haken. H., a German physicist, founded the science of synergetics in the 70 s of $20^{\text {th }}$ century. He said: the synergy is the mutual coordinative, cooperative, and simultaneous combined effect between lots of sub-systems in one system. It is an inherent express of system integrity and relevance. These sub-systems influence each other by means of exchange of materials, energies, and information, forming an integrity effect or a new structure by means of mutual effects (Haken, H., 1977). The synergetics focus on the complex system composed by sub-systems by means of complicated ways and mutual effects. These systems generate the synergetic phenomena and the coherence effect by means of nonlinear effect under certain conditions, driving systems to the orderly sate from the disordered state and possessing the function of self-organization. Haken. H. found that the absence of equilibrium is not a necessary condition for the emergence of orderly structure. The key is not whether the thermodynamics is in equilibrium or how far it is from the equilibrium. The key is the "synergetic effect" among sub-systems (Haken, H., 1977). The theory also points out whether systems experience phase transition or not is determined by the parameters controlled by systems. The phase transition of systems is realized by systems' self-organization. What kind of orders and structures systems would reach depends on the synergetic effect of internal variables as systems are in the critical region. In the vicinity of critical point, the internal variables of systems include slow relaxation variables and fast relaxation variables. Slow relaxation variables, called order parameters, are fundamental, which determine the evolution of systems. For systems from disorderly to orderly, the key is the synergetic effect between order parameters, which determine the features and the laws of systems' evolution (Haken, H., 1983; Haken, H., 1988). The synergetics emphasizes on the integration of systems. According to theories of synergetics, the "synergy" between sub-systems and components of one system turns the disorderly state into the orderly one, changing the scattered or even contradictory components into the orderly integrated power and form the integral function. Otherwise, there is no way forming the integrated power, or integrated function or benefits (Peng Li, 2005).

According to the theories of synergetics (Haken, H.), the self-organizing evolution of industry system is essentially the self-adjustment, re-engineering, and update of industrial structure within the industry system. And the evolution and update of industrial structure is the result of components in the whole economic system, such as materials, information, energies, science \& technology, and talents, distributing in each sub-industry-system. Therefore, if any sub-industry- system hopes to develop more orderly, it must be more open and keep in exchanging materials, information, energies, science \& technology, and talents with other sub-system. By this way, it can form a structure or possess a function that is more beneficial to the orderly development of the sub-system, so that the sub-system and the whole system can achieve a synergetic development, realizing the optimal economic benefits at the same time.

\section{A model to assess the synergy degree of the primary-tertiary industry system}

\subsection{The order-degree model of the primary industry system}

In the development of the primary industry system, suppose the order parameters are $\mathrm{e}_{1}=\left(\mathrm{e}_{11},{ }_{12}, \ldots, \mathrm{e}_{\mathrm{n}}\right)$, and $\mathrm{n} \geq 1, \beta_{1 \mathrm{i}} \leq \mathrm{e}_{1 \mathrm{i}} \leq \alpha_{1 \mathrm{i}}, \mathrm{i} \in[1, \mathrm{n}]$. In this paper, the order parameters of the primary industry system could be taken as the indexes evaluating the development of primary industry. Suppose $e_{11}, 12, \ldots, e_{1 j}$ are slow relaxation parameters, and the higher their values are, the higher the order degree of the system is, and the smaller their values are, the lower the order degree of the system. Suppose $e_{1 j+1},{ }_{1 j+2}, \ldots, e_{1 n}$ are fast relaxation parameters, and the higher their values are, the lower the order degree of the system is, and the smaller their values are, the higher the order degree of the system. Therefore, define it as follow:

Definition 1. The formula represents the order degree of system by the order parameter $\mathrm{e}_{1 \mathrm{i}}$ of the primary industry system 


$$
u_{1}\left(e_{1 i}\right)=\left\{\begin{array}{l}
\frac{e_{1 i}-\beta_{1 i}}{\alpha_{1 i}-\beta_{1 i}}, i \in[1, j] \\
\frac{\alpha_{1 i}-e_{1 i}}{\alpha_{1 i}-\beta_{1 i}}, i \in[j+1, n]
\end{array}\right.
$$

From the Definition 1, we know that the larger the value of $\mathrm{u}_{1}\left(\mathrm{e}_{1 \mathrm{j}}\right) \in[1, \mathrm{n}]$ is, the bigger the "contribution" of $\mathrm{e}_{1 \mathrm{i}}$ to the orderly state of the primary industry system. Here we should notice that in practice it is no good for the value of $\mathrm{e}_{1 \mathrm{i}}$ too big or too small. The best is to center in certain range. For this kind of $\mathrm{e}_{1 \mathrm{i}}$, we can adjust the range of value $\left[\beta_{1 i}, \alpha_{1 i}\right]$ to make the order degree to fit the Definition 1 . In general, the "total contribution" of order parameter $\mathrm{e}_{1 \mathrm{i}}$ to the order degree of the primary industry system can be realized by the integration $\mathrm{u}_{1}\left(\mathrm{e}_{1 \mathrm{i}}\right)$. However, the "integration" rules are determined by the fact that the systems have different structures. To make it simple, in this paper authors process it by geometric mean method:

$$
u_{1}\left(e_{1}\right)=\sqrt[n]{\prod_{j=1}^{n} u_{1}\left(e_{1 j}\right)}
$$

Definition 2: Take $\mathrm{u}_{1}\left(\mathrm{e}_{1}\right)$ defined above as the order degree of the primary industry system.

From Definition 2, we know if $\mathrm{u}_{1}\left(\mathrm{e}_{1}\right) \in[0,1]$, the larger the $\mathrm{u}_{1}\left(\mathrm{e}_{1}\right)$ is, the bigger the "contribution" of $\mathrm{e}_{1}$ to the order degree of the primary industry system is, and the higher the order degree of the system is, vice verse.

\subsection{The order-degree model of the tertiary industry system}

Similar to the assumption for the order-degree model of the primary industry system, then:

Definition 3: The following formula is the order degree of system by the order parameter $\mathrm{e}_{2 \mathrm{i}}$ of the tertiary industry system.

$$
u_{2}\left(e_{2 i}\right)=\left\{\begin{array}{l}
\frac{e_{2 i}-\beta_{2 i}}{\alpha_{2 i}-\beta_{2 i}}, i \in[1, j] \\
\frac{\alpha_{2 i}-e_{2 i}}{\alpha_{2 i}-\beta_{2 i}}, i \in[j+1, n]
\end{array}\right.
$$

Definition 4: Take $\mathrm{u}_{2}\left(\mathrm{e}_{2}\right)$ defined in the following formula as the order degree of the tertiary industry system.

$$
u_{2}\left(e_{2}\right)=\sqrt[n]{\prod_{j=1}^{n} u_{2}\left(e_{2 j}\right)}
$$

From Definition 4, we know if $\mathrm{u}_{2}\left(\mathrm{e}_{2}\right) \in[0,1]$, the larger the $\mathrm{u}_{2}\left(\mathrm{e}_{2}\right)$ is, the bigger the "contribution" of $\mathrm{e}_{2 \mathrm{i}}$ to the order degree of the tertiary industry system is, and the higher the order degree of the system is, vice verse.

\subsection{The synergy-degree model of the primary-tertiary industry system}

The synergy degree of primary-tertiary industry system means the degree of harmony and unity of the primary industry system and the tertiary industry system in the process of independent development and evolvement by means of mutual effects. It determines the tendency and the degree of the primary-tertiary industry system from disorderly to orderly state.

Suppose at the initial moment (or certain specific time period) $t_{0}$, the order degree of the primary industry system is $\mathrm{u}_{1}{ }^{0}\left(\mathrm{e}_{1}\right)$, and the order degree of the tertiary industry system is $\mathrm{u}_{2}{ }^{0}\left(\mathrm{e}_{2}\right)$. But at the moment $\mathrm{t}_{1}$ during the evolvement of the entire primary-tertiary industry system, if the order degree of the primary industry system is $\mathrm{u}_{1}{ }^{1}\left(\mathrm{e}_{1}\right)$, and the order degree of the tertiary industry system is $\mathrm{u}_{2}{ }^{1}\left(\mathrm{e}_{2}\right)$, then:

Definition 5: The synergy degree of sub-systems in the primary-tertiary industry system:

$$
X T D=\lambda \cdot \sqrt{\left|u_{1}^{1}\left(e_{1}\right)-u_{1}^{0}\left(e_{1}\right)\right| \times\left|u_{2}^{1}\left(e_{2}\right)-u_{2}^{0}\left(e_{2}\right)\right|}
$$

Here,

$$
\lambda=\left\{\begin{array}{l}
1, \quad\left[u_{1}^{1}\left(e_{1}\right)-u_{1}^{0}\left(e_{1}\right)\right] \times\left[u_{2}^{1}\left(e_{2}\right)-u_{2}^{0}\left(e_{2}\right)\right]>0 \\
-1, \quad\left[u_{1}^{1}\left(e_{1}\right)-u_{1}^{0}\left(e_{1}\right)\right] \times\left[u_{2}^{1}\left(e_{2}\right)-u_{2}^{0}\left(e_{2}\right)\right] \leq 0
\end{array}\right.
$$

Explanations for Definition 5: 
First, for $\mathrm{XTD} \in[-1,1]$, the larger the value is, the higher the synergy degree of the entire primary-tertiary industry system is, vice verse.

Second, the parameter $\lambda$ is to judge the synergy direction of the primary industry sub-system and the tertiary industry sub-system. As $\left[\mathrm{u}_{1}{ }^{1}\left(\mathrm{e}_{1}\right)-\mathrm{u}_{1}{ }^{0}\left(\mathrm{e}_{1}\right)\right] \times\left[\mathrm{u}_{2}{ }^{1}\left(\mathrm{e}_{2}\right)-\mathrm{u}_{2}{ }^{0}\left(\mathrm{e}_{2}\right)\right]>0$, the XTD reflects the synergy degree of two subsystems toward the same direction. As $\left[\mathrm{u}_{1}{ }^{1}\left(\mathrm{e}_{1}\right)-\mathrm{u}_{1}{ }^{0}\left(\mathrm{e}_{1}\right)\right] \times\left[\mathrm{u}_{2}{ }^{1}\left(\mathrm{e}_{2}\right)-\mathrm{u}_{2}{ }^{0}\left(\mathrm{e}_{2}\right)\right] \leq 0$, the XTD reflects the opposite direction of two sub-systems or complete discordance.

Third, as both $\left[\mathrm{u}_{1}{ }^{1}\left(\mathrm{e}_{1}\right)-\mathrm{u}_{1}{ }^{0}\left(\mathrm{e}_{1}\right)\right]$ and $\left[\mathrm{u}_{2}{ }^{1}\left(\mathrm{e}_{2}\right)-\mathrm{u}_{2}{ }^{0}\left(\mathrm{e}_{2}\right)\right]$ are larger than zero, the XTD reflects the synergy degree of two sub-systems developing toward low orderly state. As both $\left[\mathrm{u}_{1}{ }^{1}\left(\mathrm{e}_{1}\right)-\mathrm{u}_{1}{ }^{0}\left(\mathrm{e}_{1}\right)\right]$ and $\left[\mathrm{u}_{2}{ }^{1}\left(\mathrm{e}_{2}\right)-\mathrm{u}_{2}{ }^{\gamma}\left(\mathrm{e}_{2}\right)\right]$ are smaller than zero, the XTD reflects the synergy degree of two sub-systems developing toward high orderly state.

Fourth, the Definition 5 discusses conditions of two sub-systems. If the order degree of one sub-system rises significantly and the order degree of the other sub-system rises slightly, the entire system can not stay in a good synergetic state. Besides, to master the synergy state of the entire industry system in the changes of order degree is a dynamic analysis process for the entire system.

\section{The empirical study on Dujiangyan City}

In order to study the synergy degree of the primary-tertiary complex industry system, we must build a proper index system. According to the self-organization and self-adaptation characteristics of complex system, this paper is based on theories of order parameters from synergetics and theories of dominance, and build a synergy degree model for the primary-tertiary industry system.

\subsection{Selection of order parameter indexes}

The industry order degree reflects the closeness degree of one country or region's industrial structure to the target structure, which can be used to measure the reasonability level of industrial structure. By analyzing the changes of order degree of industrial structure, we can exactly master and judge whether the direction of industrial structure is proper or not (Haibiao Huang \& Jun $\mathrm{Li}$, 2008). If the primary-tertiary complex industry system pursues for synergy development, first of all, the primary industry system and tertiary industry system must realize the orderly development respectively. The components of two industries affect and promote mutually, and effectively drive the local economic development. It can reflect the local industry size and development rate, and the unity of structure, quality, and efficiency. Therefore, the selection of order parameter indexes should make sure that the indexes reflect the development of industries. In this paper, the order parameter indexes of the primary industry are proportions of added value and employers, agricultural products value, forest industry value, poultry industry value, and fishing industry value. The order parameter indexes of the tertiary industry are proportions of added value and employees, tourism industry income, consumption goods retail sales, communication income, finance and insurance, real estate investments, and transportation. Here, the proportion of added value reflects the size and rate of industrial development. The proportion of employers reflects the efficiency and quality of industrial development. And other indexes can reflect the industrial structure and synergy degree.

\subsection{Data source}

Considering the needs of model, data in this paper are mainly from Sichuan Statistical Yearbook, Chengdu Statistical Yearbook, and Dujiangyan City Statistical Report between 2003 and 2008. Because of different targets of the order parameters, original data should be standardized. Use the formula $\mathrm{R}_{\mathrm{i}}=\left(\mathrm{e}_{\mathrm{ji}}-e_{j i}\right) / \sigma_{\mathrm{i}},(\mathrm{j}=1,2 ; \mathrm{i}=1,2, \ldots, \mathrm{n}$; $e_{j i}$ is the average; $\sigma_{\mathrm{i}}$ is the standard deviation) to make data standardization. The results are listed in Table 1.

4.3 The calculation of synergy degree of the primary-tertiary industry system

(1) The order degree of order parameters of the primary industry system. According to data in Table 1, we use the formula (1) to calculate the order degree of the primary industry system. Here, the value of $\beta_{1 \mathrm{i}}$ and $\alpha_{1 \mathrm{i}}$ is in line with the minimum and the maximum of the sequence. Results are listed in Table 2.

(2) The order degree of order parameters of the tertiary industry system. According to data in Table 1, we use the formula (3) to calculate the order degree of the tertiary industry system. Here, the value of $\beta_{2 i}$ and $\alpha_{2 i}$ is in line with the minimum and the maximum of the sequence. Results are listed in Table 3.

(3) The calculation of synergy degree of the primary-tertiary industry system. First of all, use formula (2) and (4) to calculate the order degree of primary-tertiary industry system. Results are displayed in Figure 1 and 2. Then, take the order degree of primary industry sub-system and that of tertiary industry sub-system as the intermediate variables, and the year 2003 as the base year. Use the formula (5) to calculate the synergy degree of primary-tertiary complex industry system. See to Figure 3. Because certain sub-order parameter may make the order degree be 0 , authors change this kind of indexes to 0.0001 , in order to avoid the emergence of 0 order degree, as we use geometric mean method to calculate the order degree of the entire industry system.

\subsection{Results analysis}

Figure 1 shows that from 2003 to 2008, the order degree of the primary industry system is generally rising. In 2007, it fluctuates and decreases slightly, which means the synergetic effect of all order parameters in the system 
is inefficient. According to the order degree of sub-order parameter of the primary industry system, the order parameter ------ the proportion of employees from the primary industry ------ develops disorderly, which indicates unreasonable employment structure of the primary industry. Employees in the primary industry continue to decrease, and the decrease does not fit for the needs of primary industry development. Employment structure mainly reflects the development efficiency of one industry. It decreases its contribution to the order degree of the system. It proves that big changes of each order parameter will affect the order degree of the primary industry system.

Figure 2 shows that from 2003 to 2007, the order degree of the tertiary industry system is in a fast growing state. In 2008, the order degree of tertiary industry system drops severely. According to the order parameters of the tertiary industry system, the order degrees of all order parameters in 2008 are decreasing. These order parameters affect the contribution ratio from different perspectives. As a result, the order degree of the whole industry system develops toward a reasonable direction. The reason is that Dujiangyan City has suffered from huge earthquake in 2008. All kinds of resources, especially the touring resources, were damaged on different level. Plus, infrastructure and roads collapse. It seriously affects the development of tourism-dominating tertiary industry in Dujiangyan City.

Figure 3 shows that the synergy development of the primary-tertiary complex industry system in Dujiangyan City rises firstly and then decreases. From 2004 to 2006, the synergy degree of complex system is generally in a rising state. From 2007, it starts to decline and in 2008 it drops heavily. From Figure 1 and 2, although the order degree of the tertiary industry system is highest in 2007, the low order degree of the primary industry system causes a slight decrease of synergy degree of the primary-tertiary industry system. But in 2008 the fast drop of order degree of tertiary industry system causes a huge reduce of synergy degree of the primary-tertiary industry system, making the primary-tertiary industry system be in a low-synergetic development state.

Generally speaking, the average synergy degree of the primary-tertiary industry system in Dujiangyan City between 2003 and 2008 is only 0.2441 , which means the primary-tertiary complex industry system in Dujiangyan City is in a synergetic development, though the synergy degree is low.

\section{Conclusions and suggestions}

Based on theories of synergetics, authors constitute a mathematical model and analyze the synergy degree of the primary-tertiary complex industry system in Dujiangyan City. Studies show that the primary-tertiary industry system in Dujiangyan City has a positive synergy degree, but the synergy degree is low, which means there is no efficient synergetic relationship between the two industry systems. Therefore, the employment structure is unreasonable and so does the industrial structure. By analyzing the resources and endowments of Dujiangyan City, we know that special agricultural industries and tourism industry are dominating, especially the tourism industry, which is treated as a leading industry in practice. However, the analysis results do not prove the two industries' contributions respectively to their industry system.

Therefore, authors suggest that we must think about the resources and endowments of Dujiangyan City, focus on farmers' employment issue, try every means to improve farmers' quality, increase trainings, and develop labor-intensive industries, in order to promote the synergetic development of the primary-tertiary industry, improve farmers' income, and solve the "agriculture, rural areas, and farmers" problem. By means of applying the agricultural industrialization, we should develop special agriculture in Dujiangyan City. For example, develop the five special advantage industries, such as kiwi fruit, tea, cold water fish, pigs, vegetables, and edible fungi, and make the production of primary industry progress toward an advanced stage. Meanwhile, develop the tourism-leading modern service industry, especially the special tourism industry, such as county touring and farmers' house, driving and serving the development of relevant industries and sectors, and promoting the synergetic development of the primary-tertiary industry.

\section{References}

Haken, H. (1977). Synergetic ------ An Introduction. Berlin: Springer.

Haken, H. (1983). Advanced Synergetics. Berlin: Springer.

Haken, H. (1988). Information and Self-Organization. Berlin: Springer.

Huang, Haibiao \& Li, Jun. (2008). On the constitution of index system for assessing the optimization and update of industrial structure. Commercial Times, No.3.

Li, Peng. (2005). Theoretical basis and practical methods of regional economic synergistic development. Geography and Geo-Information Science, No.4.

Statistical Report on National Economy and Social Development in Dujiangyan City in 2009. [Online] Available: http://tjj.djy.gov.cn/html/ tongjigongbao/201008/16-33.html 
Table 1. Order parameters of the synergy development of the primary-tertiary industry system

\begin{tabular}{|c|c|c|c|c|c|c|c|}
\hline \multirow[b]{2}{*}{ Year } & \multicolumn{7}{|c|}{ Order parameters of the primary industry system } \\
\hline & $\begin{array}{l}\text { The } \\
\text { proportion of } \\
\text { primary } \\
\text { industry } \\
\text { added value } \\
\text { to GDP }\end{array}$ & $\begin{array}{l}\text { Proportion } \\
\text { of } \\
\text { employees } \\
\text { from } \\
\text { primary } \\
\text { industry } \\
\end{array}$ & $\begin{array}{l}\text { Agricultural } \\
\text { product } \\
\text { value }\end{array}$ & $\begin{array}{l}\text { Forest } \\
\text { industry } \\
\text { value }\end{array}$ & $\begin{array}{l}\text { Poultry } \\
\text { industry } \\
\text { value }\end{array}$ & $\begin{array}{l}\text { Fishing } \\
\text { industry } \\
\text { value }\end{array}$ & $\begin{array}{l}\text { Total } \\
\text { powers of } \\
\text { agriculture } \\
\text { machine }\end{array}$ \\
\hline 2003 & -0.5501880 & 0.5110971 & 145 & -0.7941067 & 9884 & -0.6620664 & 829 \\
\hline 2004 & -0.7895040 & 0.2231684 & -0.5303197 & -0.7411662 & -0.7097971 & -0.4706255 & 0.0000000 \\
\hline 2005 & 0.0190554 & -0.3870263 & -0.5630106 & -0.3705831 & -0.3952087 & -0.2791846 & 0.0000000 \\
\hline 2006 & -0.3668243 & -0.7122364 & -0.1380284 & -0.1588213 & -0.1042990 & 0.0558369 & 0.0000000 \\
\hline 2007 & -0.2777176 & -1.2255663 & 1.4856215 & 1.9058560 & 0.9916864 & 1.9702458 & 0.5976143 \\
\hline 2008 & 1.9651785 & 1.5905636 & 0.9080816 & 0.1588213 & 1.3976069 & -0.6142062 & 1.1952286 \\
\hline
\end{tabular}

\begin{tabular}{|c|l|l|l|l|l|l|l|}
\hline & \multicolumn{9}{|l|}{ Order parameters of the tertiary industry system } & \\
\cline { 2 - 8 } Year & $\begin{array}{l}\text { The } \\
\text { proportion } \\
\text { of tertiary } \\
\text { industry } \\
\text { added } \\
\text { value } \\
\text { GDP }\end{array}$ & $\begin{array}{l}\text { Proportion } \\
\text { of } \\
\text { employees } \\
\text { from } \\
\text { tertiary } \\
\text { industry }\end{array}$ & $\begin{array}{l}\text { Real estate } \\
\text { investment }\end{array}$ & $\begin{array}{l}\text { Tourism } \\
\text { industry } \\
\text { income }\end{array}$ & $\begin{array}{l}\text { Consumption } \\
\text { goods retail } \\
\text { sales }\end{array}$ & $\begin{array}{l}\text { Communication } \\
\text { income }\end{array}$ & $\begin{array}{l}\text { Finance and } \\
\text { insurance }\end{array}$ \\
\hline 2003 & -0.8734558 & -0.6917818 & -1.1280031 & -1.1265697 & -0.9286169 & -1.6207599 & -0.7657886 \\
\hline 2004 & 1.3911382 & -0.7384345 & -0.7321174 & -0.5769284 & -0.3653015 & 0.0373816 & -0.6590138 \\
\hline 2005 & 0.3132963 & -0.3696104 & -0.3619914 & -0.3266662 & 0.2799507 & 1.2068920 & -0.4551399 \\
\hline 2006 & 0.3635536 & -0.1341185 & 0.6480595 & 0.2218056 & 0.5987360 & 0.6782092 & -0.1185375 \\
\hline 2007 & 0.2267576 & -0.0208231 & 1.6242160 & 1.8005624 & 1.5269262 & 0.3017230 & 0.0608624 \\
\hline 2008 & -1.4212898 & 1.9547683 & -0.0501636 & 0.0077963 & -1.1116945 & -0.6034460 & 1.9376174 \\
\hline
\end{tabular}

Table 2. The calculation results of order parameters of the primary industry sub-system

\begin{tabular}{|c|c|c|c|c|c|c|c|}
\hline \multirow[b]{2}{*}{ Year } & \multicolumn{7}{|c|}{ The order degree of sub-order parameters of the primary industry system } \\
\hline & $\begin{array}{l}\text { The } \\
\text { proportion } \\
\text { of primary } \\
\text { industry } \\
\text { added value } \\
\text { to GDP }\end{array}$ & $\begin{array}{l}\text { Proportion } \\
\text { of } \\
\text { employees } \\
\text { from } \\
\text { primary } \\
\text { industry }\end{array}$ & $\begin{array}{l}\text { Agricultural } \\
\text { product } \\
\text { value }\end{array}$ & $\begin{array}{l}\text { Forest } \\
\text { industry } \\
\text { value }\end{array}$ & $\begin{array}{l}\text { Poultry } \\
\text { industry } \\
\text { value }\end{array}$ & $\begin{array}{l}\text { Fishing } \\
\text { industry } \\
\text { value }\end{array}$ & $\begin{array}{l}\text { Total } \\
\text { powers of } \\
\text { agriculture } \\
\text { machine }\end{array}$ \\
\hline 2003 & 0.0869 & 0.6167 & 0.0000 & 0.0000 & 0.0000 & 0.0000 & 0.0000 \\
\hline 2004 & 0.0000 & 0.5144 & 0.2387 & 0.0196 & 0.1824 & 0.0727 & 0.6000 \\
\hline 2005 & 0.2935 & 0.2978 & 0.2263 & 0.1569 & 0.3045 & 0.1455 & 0.6000 \\
\hline 2006 & 0.1534 & 0.1823 & 0.3868 & 0.2353 & 0.4173 & 0.2727 & 0.6000 \\
\hline 2007 & 0.1858 & 0.0000 & 1.0000 & 1.0000 & 0.8425 & 1.0000 & 0.8000 \\
\hline 2008 & 1.0000 & 1.0000 & 0.7819 & 0.3529 & 1.0000 & 0.0182 & 1.0000 \\
\hline
\end{tabular}


Table 3. The calculation results of order parameters of the tertiary industry sub-system

\begin{tabular}{|l|l|l|l|l|l|l|l|}
\hline & \multicolumn{2}{|l|}{ The order degree of sub-order parameters of the tertiary industry system } & \\
\hline Year & $\begin{array}{l}\text { The } \\
\text { proportion } \\
\text { of tertiary } \\
\text { industry } \\
\text { added } \\
\text { value } \\
\text { GDP }\end{array}$ & $\begin{array}{l}\text { Proportion } \\
\text { of } \\
\text { employees } \\
\text { from } \\
\text { tertiary } \\
\text { industry }\end{array}$ & $\begin{array}{l}\text { Real estate } \\
\text { investment }\end{array}$ & $\begin{array}{l}\text { Tourism } \\
\text { industry } \\
\text { income }\end{array}$ & $\begin{array}{l}\text { Consumption } \\
\text { goods retail } \\
\text { sales }\end{array}$ & $\begin{array}{l}\text { Communication } \\
\text { income }\end{array}$ & $\begin{array}{l}\text { Finance } \\
\text { and } \\
\text { insurance }\end{array}$ \\
\hline 2003 & 0.1948 & 0.0173 & 0.0000 & 0.0000 & 0.0694 & 0.0000 & 0.0000 \\
\hline 2004 & 1.0000 & 0.0000 & 0.1438 & 0.1878 & 0.2829 & 0.5864 & 0.0395 \\
\hline 2005 & 0.6168 & 0.1369 & 0.2783 & 0.2733 & 0.5274 & 1.0000 & 0.1149 \\
\hline 2006 & 0.6346 & 0.2244 & 0.6453 & 0.4606 & 0.6482 & 0.8130 & 0.2394 \\
\hline 2007 & 0.5860 & 0.2665 & 1.0000 & 1.0000 & 1.0000 & 0.6799 & 0.3058 \\
\hline 2008 & 0.0000 & 1.0000 & 0.3916 & 0.3875 & 0.0000 & 0.3598 & 1.0000 \\
\hline
\end{tabular}

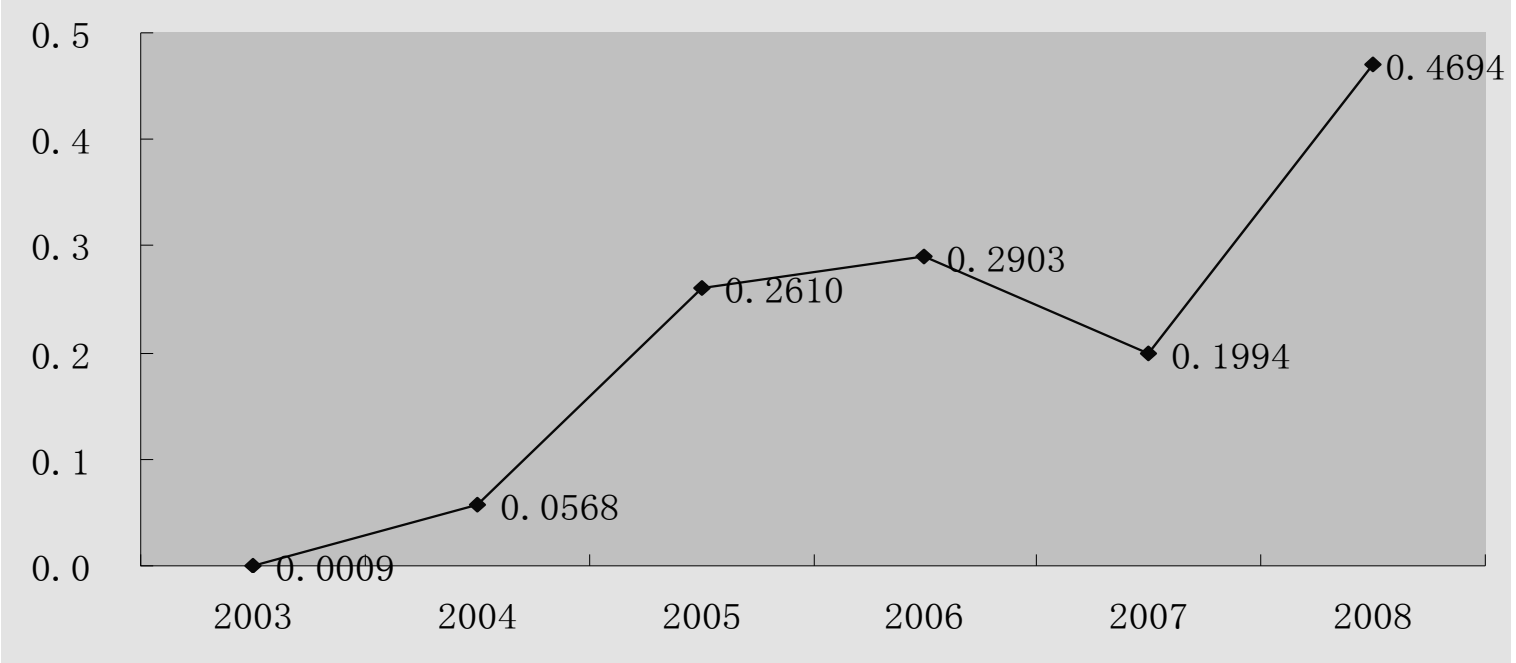

Figure 1. The Line Graph for the Order Degree of the Primary Industry System

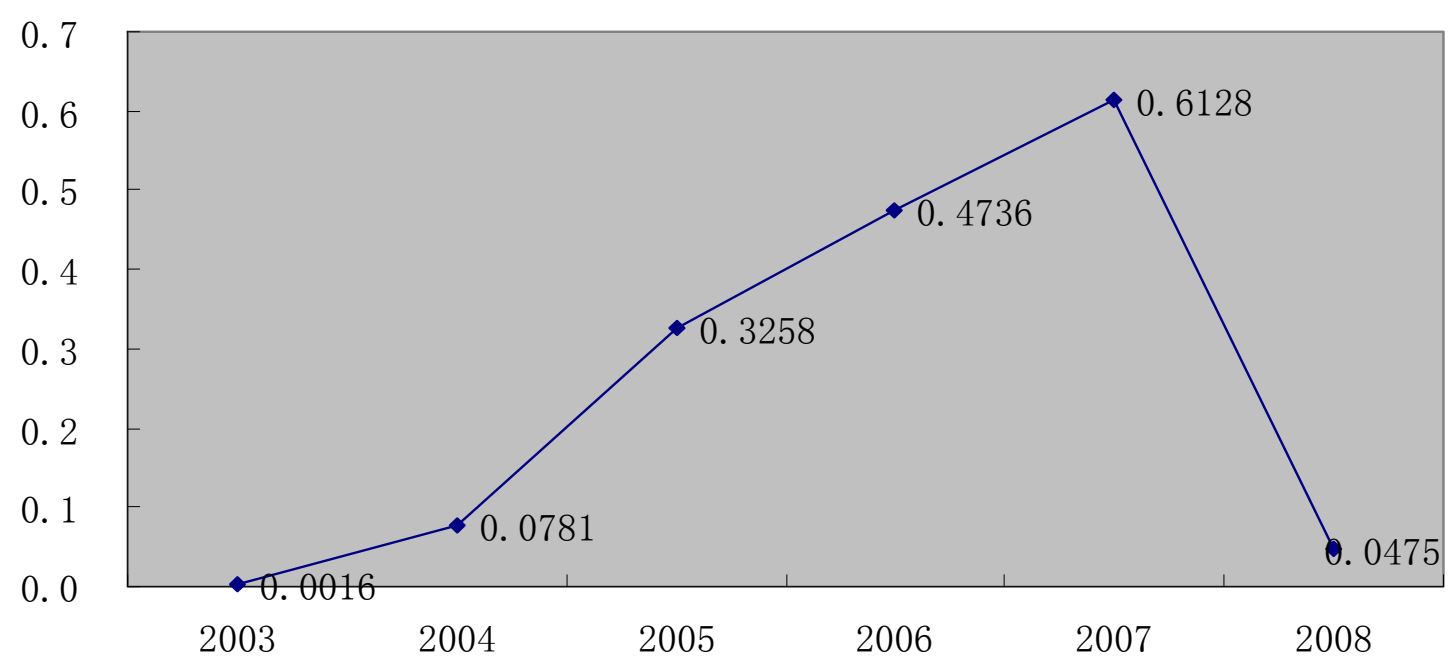

Figure 2. The Line Graph for the Order Degree of the Tertiary Industry System 